\title{
The Neutrality of International Courts and Tribunals: Why and to What Degree?
}

\author{
Merve Ozkan Borsa
}

\begin{abstract}
It goes without saying that the principle of separation of powers leads to an independent judiciary imposing the rule of law and thereby assurance for the society so as to be prevented against any abuse of power, which is an integral part and a must of democratic values. This independence and impartiality crystallize as to the degree the judiciary (as an institution) and individual judges are able to hold responsibility without being influenced or intervened by any other source. The confidence of the society and the maitenance of justice can only be ensured provided that this independence and impartiality is taken under guarantee by binding instruments and that the manner in which jurisdiction is performed is carried out in accordance to such requirement. Nevertheless, the author of this paper claims that if meant to remain pretty much uncontested, such rhetoric holds true merely for domestic law, since I believe there is reasonable ground to state that this idea -and "ideal" too, since it has also reached such a level-, is relevant mainly for the domestic laws, dissenting from international law; like the title of the article provocatively illustrates. Likewise, there has been theoretical objections asserting that independence, impartiality and neutrality of international courts and tribunals is not required for fair decisions, justice or the court's effectiveness.
\end{abstract}

Keywords: Neutrality International Courts Tribunals

\section{Introduction}

As regards to above objections, two main critiques can be introduced:

For the first type of objection, it is possible to note that law -not limited to international law but as a "logic"-, most of the time cannot -if not "never"- be free from external factors such as conjoncture, the demands of society, power struggles and alike. This state of affair enables alleging indecency of neutrality and independence of international courts, because, -since we are not in an era of natural or divine law which is based on human conscience, theology or any other origins similar to those-, "law" itself has been a phenomenon constructed depending upon and in relation to such influences. And what the law actually does is merely to mask and sustain the inequality and oppression characteristic of capitalist society. Under such circumstances, the judges to be dependent on some factors like moral ideals, ideological imperatives or certain interests and alike that influence their judgments -though theoretically speaking-can be justifiable and even demandable in the name of eroding the current unequalities and unfairness by re-distributing the justice to reach de lege feranda -under the assumption that the influences are not further deepening the existing negative features of the current situation-. This way, by the judges who are belonging to different cultures; different moral systems will be able to be represented in the court and this will open a way for different moralities to tahe the scene, since current law represents the value prevalent in certain geographies. The phenomenon of "international community"s becoming a matter of discussion can be used as a supportive argument for this objection. On the other hand, a counter-argument -amongst others-, can be developed to challenge this view by expressing that it ignores the consensual characteristic of international law.

A second main objection can be founded on the basis of an utalitarian perspective. Such perspective suggests that an international court can be effectively working only when instruments have been set up as to allow the court's jurisdiction to be open to the influence of governments and when the judges can closely be controlled by governments. The main reason for this, according to the approach, is the argument that if the governments can influence the decision of the Court, they become more willing to resort to the Court. This approach can be supported by the theory of "constrained independence". According to this theory, states create independent international tribunals aiming at enhancing the credibility of their commitments in multilateral settings and then they limit the potential for judicial overreaching by structural, political, and discursive mechanisms. As opposed to that, it is possible to challenge utalitarian objection by the evidence of some states' resorting to international courts -or establishing them in the very beginning- without any opportunity and facility as claimed. 
The application impediments, on the other hand, possess a variety of difficulties ranging from physical shortcomings to structural inadequacies, from the minor and basic ones to the major and unchangables.

All in all, while implying a positive sense regarding justice, effectivity, integrity and credibility, but not exempted from neither theoretical objections nor application impediments, the issue of independence, impartiality and neutrality of international courts and tribunals and their judges has been a moot question in the area of international legal interactions. In this paper, the issue of neutrality of international law will be evaluated by the inquiry of the current and possible theoretical and ampirical/practical objections towards the nearly uncontested dictum and assertion of the (necessity of and) neutrality of international courts and tribunals. The title asks the question of why and to what degree international courts and tribunals are neutral. In this case, the theoretical objections will be explored for discussing the first interrogative article (why should international courts and tribunals be neutral?), while the study on ampirical objections will pave way for discussing the second. At the same time, counter-arguments will also be developed towards each of the objections. 